\section{Wide Spread Arterial and Ve- nous Thrombosis in a Case of Hyperglycemic Hyperosmolar State (HHS)}

\author{
Ganaw $A^{1^{*}}$, Shaikh $\mathbf{N}^{1}$, Marcus $\mathrm{AE}^{1}$ and Soekarman $\mathrm{D}^{2}$ \\ ${ }^{1}$ Department of Anesthesia, ICU and Perioperative Medicine, Hamad Medi- \\ cal Corporation, Weil Cornell Medical College, Doha, Qatar
}

${ }^{2}$ Department of Internal Medicine, Hamad Medical Corporation, Weil Cornell Medical College, Doha, Qatar

\begin{abstract}
A case is presented with a patient in a Hyperglycemic Crisis $(\mathrm{HC})$, complicated by widespread thrombo ischemia including the left upper and lower limb, and the aortic arch. Extreme hyperglycemia and dehydration added to the pro-thrombotic state of diabetes and resulted in lower limb ischemia with ultimate limb loss. Current guidelines provide for thrombo-prophylaxis against Deep Venous Thrombosis (DVT) in HHS. Further development of the guidelines is needed to cover the risk of an arterial thrombosis as well.
\end{abstract}

\section{Introduction}

Diabetes mellitus is regarded as a pro-thrombotic state [1]. Extreme hyperglycemia and dehydration in the Hyperglycemic Hyperosmolar State (HHS), a subtype of Hyperglycemic Crisis (HC), add to the risk for thrombo-ischemic events [2]. Lower limb ischemia and occlusion of the femoral arteries in HHS is a distinct

*Corresponding author: Ganaw A, Department of Anesthesia, ICU and perioperative medicine, Hamad Medical Corporation, Doha, Qatar, Tel: + 97433605110; E-mail: AGanaw@hamad.qa

Citation: Ganaw A, Shaikh N, Marcus AE, Soekarman D (2018) Wide Spread Arterial and Venous Thrombosis in a Case of Hyperglycemic Hyperosmolar State (HHS) 5: 027

Received: March 26, 2018; Accepted: April 30, 2018; Published: May 14, 2018 association, but its development may be hard to recognize due to its infrequent occurrence in daily practice $[3,4]$. Prompt recognition is important, since the window of opportunity to prevent irreversible damage is narrow. For teaching purposes, the following case is reported.

\section{Case Presentation}

A 50 years old female was admitted to the intensive care unit with polyuria and polydipsia, epigastric abdominal pain, vomiting and dizziness since 1 day. She had been successfully treated for carcinoma of the uterus, 1 year prior to the current episode. She reported no other medical conditions except for high blood pressure. Clinical examination showed a fully conscious female who was severely dehydrated. Clinical and laboratory parameters on admission are represented in table 1 . Based on a glucose level $>30 \mathrm{mmol} / \mathrm{L}$ and an osmolarity $>320$, a Hyperglycemic Hyperosmolar State (HHS) was diagnosed. Other investigations (septic work up, chest X ray, and ECG) were normal.

\begin{tabular}{|c|c|c|}
\hline Characteristics & Clinical Parameters & Normal Range \\
\hline Age & 50 years & \\
\hline Gender & female & \\
\hline BMI & $31.1 \mathrm{Kg} / \mathrm{m}^{2}$ & \\
\hline Heart rate & 126 beats $/ \mathrm{min}$. & \\
\hline Blood pressure & $93 / 40 \mathrm{~mm} \mathrm{Hg}$. & \\
\hline Temperature & $38^{\circ} \mathrm{C}$ & \\
\hline Resp. rate & 28 breaths $/ \mathrm{min}$. & normal range \\
\hline Blood sugar & $84.4 \mathrm{mmol} / \mathrm{L}$ & $3.3-5.5 \mathrm{mmol} / \mathrm{L}$ \\
\hline Calculated osmolarity & $348.4 \mathrm{mOsm} / \mathrm{Kg}$ & $275-295 \mathrm{mOsm} / \mathrm{Kg}$ \\
\hline Sodium & $132 \mathrm{mmol} / \mathrm{L}$ & $135-145 \mathrm{mmo} / \mathrm{L}$ \\
\hline Potassium & $6.1 \mathrm{mmol} / \mathrm{L}$ & $3.5-5.5 \mathrm{mmol} / \mathrm{L}$ \\
\hline Urea & $18 \mathrm{mmol} / \mathrm{L}$ & $2.5-7.1 \mathrm{mmol} / \mathrm{L}$ \\
\hline Creatinine & $312 \mu \mathrm{mol} / \mathrm{L}$ & $50-98 \mu \mathrm{mol} / \mathrm{L}$ \\
\hline Leucocytes & $23 \times 10^{9} / \mathrm{L}$ & $4-10 X 10^{9} / \mathrm{L}$ \\
\hline Platelets & $425 \times 10^{3}$ & $150-400 \times 10^{3}$ \\
\hline Serum Lipase & $1400 \mathrm{IU} / \mathrm{L}$ & $13-60 \mathrm{IU} / \mathrm{L}$ \\
\hline \multicolumn{2}{|r|}{ Table 1: Characteristics of the patient. } \\
\hline
\end{tabular}

The patient was admitted into the ICU and received a total of 9 liters of $0.9 \%$ saline I.V. with insulin/potassium and Esmoprazole 20 $\mathrm{mg}$ twice daily. Dalteparin was given subcutaneously (5000 IU daily). On the $2^{\text {nd }}$ day of admission signs of an acute ischemia were noticed in her left upper and left lower limbs. An ultrasound doppler and CT angiography confirmed the occlusion of the left subclavian and left femoral artery (Figures 1-4). Echocardiography showed a thrombus in the aortic arch. An emergency thrombectomy of the brachial and femoral arteries and a left arm fasciotomy took place and the patient was admitted into the Surgical Intensive Care Unit (SICU) for further management, Antithrombotic medication was started, unfractionated heparin infusion to keep APTT 45-70 seconds. 
Citation: Ganaw A, Shaikh N, Marcus AE, Soekarman D (2018) Wide Spread Arterial and Venous Thrombosis in a Case of Hyperglycemic Hyperosmolar State (HHS) 5: 027.

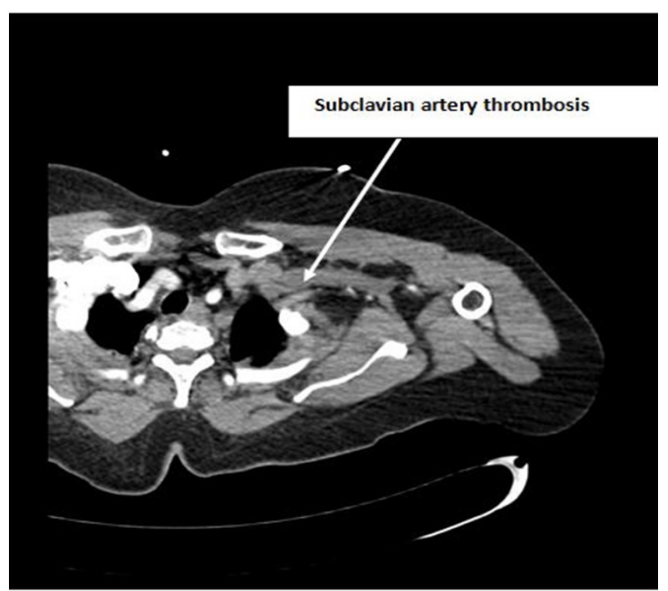

Figure 1: CT angiogram is showing subclavian artery thrombosis.

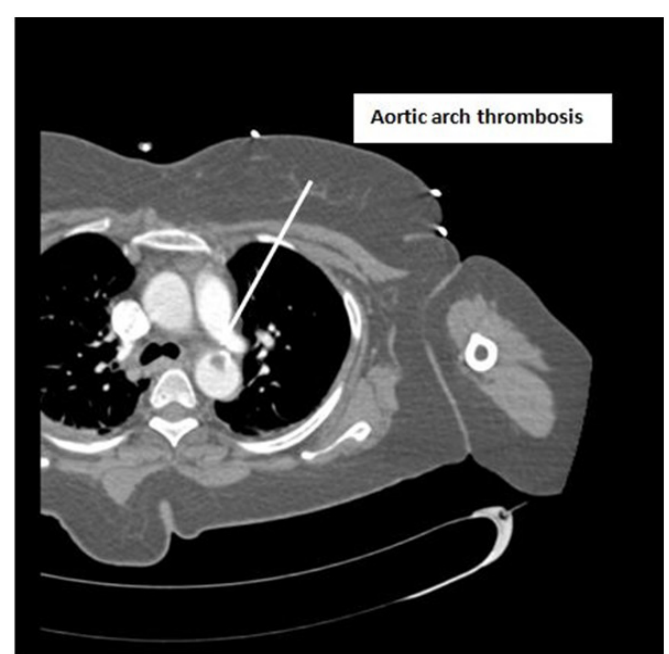

Figure 2: CT angiogram is showing Aortic arch thrombosis.

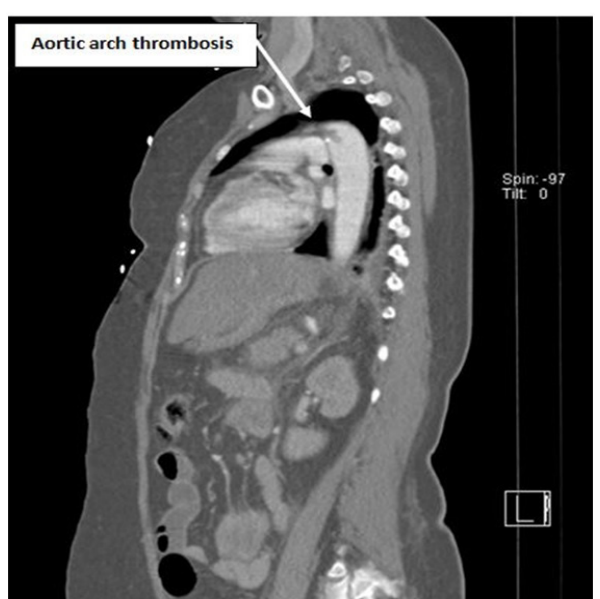

Figure 3: CT angiogram is showing Aortic arch thrombosis.

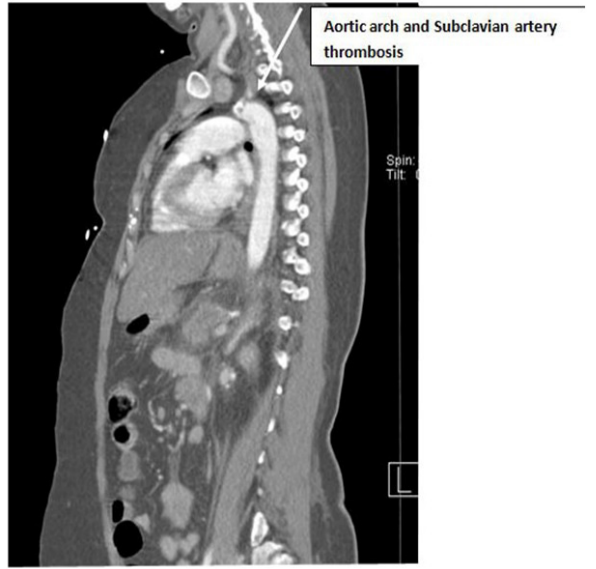

Figure 4: CT angiogram is showing Aortic arch and Subclavian artery thrombosis.

A thrombophilia work up testing for Antiphospholipid syndrome, Heparin Induced Thrombocytopenia (HIT test), Complement 3 (C3), Complement 5 (C5), Antinuclear Antibody (ANCA), lupus screen, Homocysteine, Antithrombin, Factor V Leiden, Anticardiolipin, anti B2 glycoprotein, protein S, C activity was normal. The patient and the family denied a personal or family history of thrombo-embolic events.

On the $5^{\text {th }}$ day post intensive care admission, the patient had spikes of fever $\left(39 \mathrm{C}^{\circ}\right)$, hypotension, increased WBC (13 X $\left.10^{9} / \mathrm{L}\right)$, and procalcitonin was $32 \mathrm{ng} / \mathrm{ml}$. The patient was diagnosed with a septic shock and multi-organ failure. She required high doses of Noradrenaline $(4 \mu \mathrm{g} / \mathrm{kg} / \mathrm{hr})$ and Vasopressin (0.04 IU/hour). Parameters of her coagulation profile in the first week are given in table 2. Hemodialysis was performed and Piperacillin/Tazobactam was given i.v. On the $7^{\text {th }}$ day the patient improved and she was weaned successfully from inotropic medication. Enteral feeding was started. Intravenous N-acetyl-cysteine (300mg over 24 hours) was given and her liver functions improved.

On the $9^{\text {th }}$ day the patient developed dry gangrene in the left foot, which required a below the knee amputation. On the $11^{\text {th }}$ day the patient was extubated, and a neurological assessment was showing right sided hemiparesis. The MRI was showing multiple micro cerebral hemorrhages, an infarction in the left paramedian pons and a cerebellar infarction, confirmed by CT (Figures 5 and 6). On the $14^{\text {th }}$ day the patient developed abdominal distension, epigastric tenderness, and food intolerance. The CT showed partial mesenteric vein thrombosis (Figure 7). An ultrasound of the right internal jugular vein, where the catheter was located, showed a big thrombus, despite the patient being on a therapeutic of heparin (Figure 8). Blood sugar levels were maintained between $6-10 \mathrm{mmol} / \mathrm{l}$ by titrated insulin infusion.

On the $17^{\text {th }}$ day the patient had a tracheostomy, and was discharged from the ICU for rehabilitation on a therapeutic dose of subcutaneous Dalteparin 5000 IU daily, which was continued for 3 months. On the $25^{\text {th }}$ day she was discharged home from the hospital on Warfarin, 
Citation: Ganaw A, Shaikh N, Marcus AE, Soekarman D (2018) Wide Spread Arterial and Venous Thrombosis in a Case of Hyperglycemic Hyperosmolar State (HHS) 5: 027

Amlodipine, Lisinopril, Rosuvastatin, Insulin, Propranolol and Escitalopram. The patient stayed in follow up with a visit at 3 months in the outpatient clinic. Her coagulation profile had normalized after 6 weeks (including the protein $\mathrm{C}$ activity) and her mobility kept improving. Eventually she left the country and was lost to our follow up.

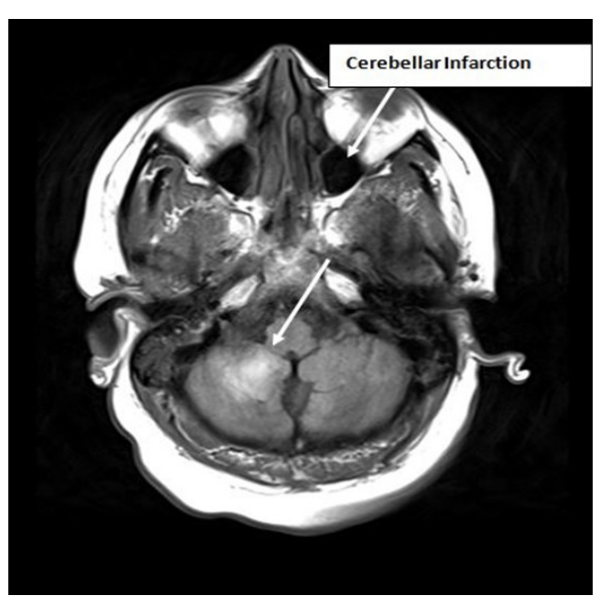

Figure 5: MRI is showing cerebellar infarction.

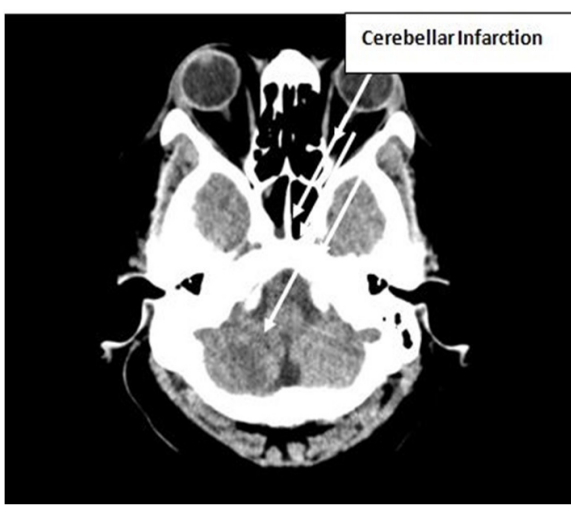

Figure 6: CT scan is showing cerebellar infarction.

\section{Discussion}

The age of onset and mode of presentation in this patient, is suggestive for an underlying type 2 diabetes [5]. Ketosis-onset diabetes, showing more similarities to type 2 than type 1 diabetes, has been associated with lower limb atherosclerotic lesions [6]. Changes of the vascular wall start at an earlier age in case of diabetes and might predispose to the formation of an arterial thrombus at certain predilection places in the arterial system [7]. In our patient thrombosis presented with upper and lower limb-ischemia on the left side. Further imaging identified a thrombus in the aortic arch as well. The number of case reports with a limb- ischemia combined with a proximal aortic thrombus is growing, supposedly due to the development of novel imaging techniques $[8,9]$. This high-risk phenotype might not be as rare as previously thought.

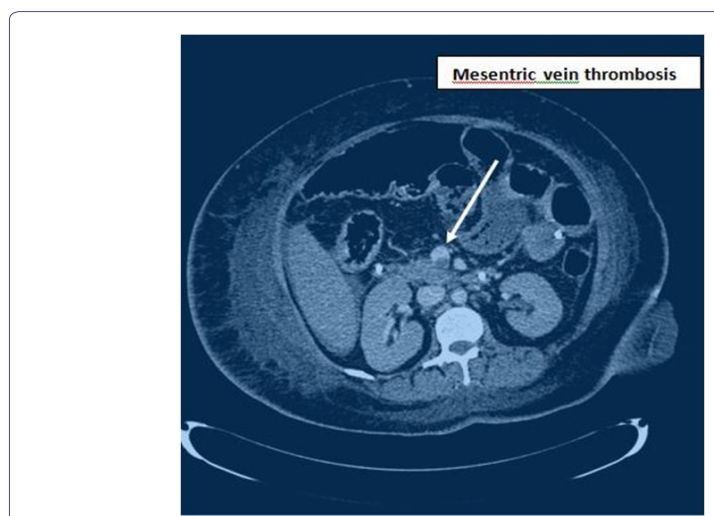

Figure 7: $\mathrm{CT}$ angiogram is showing mesenteric vein thrombosis.

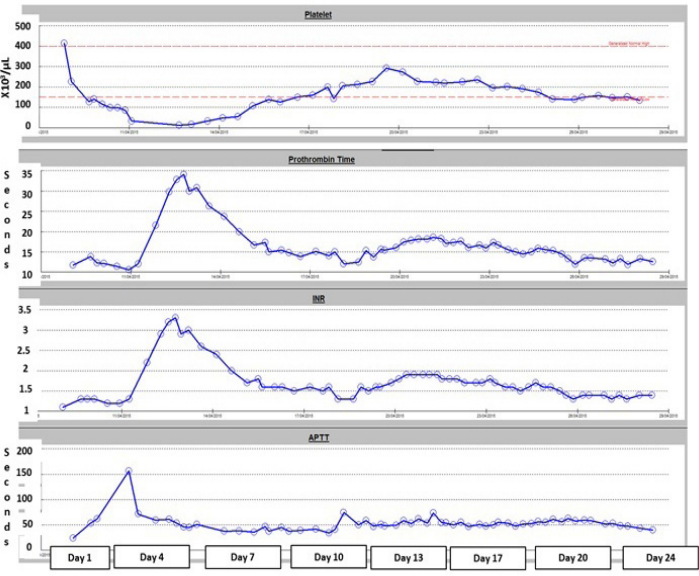

Figure 8: Coagulation during stay in intensive care unit.

Current guidelines provide for thrombo-prophylaxis in HHS, i.e., LMW Heparin during admission if no major contra-indications exist [10]. This covers the risk for a deep venous thrombosis, but might be insufficient in case of an imminent arterial thrombosis, especially in case of a long existing diabetes [11]. Alternative compounds, targeting crucial factors in the coagulation pathway leading to an arterial thrombus, should be searched for [12]. The development of an algorithm for thrombo-prophylaxis in a hyperglycemic crisis needs our ongoing attention to be able to improve the outcome of this high risk condition.

\begin{tabular}{|c|c|c|c|c|c|c|c|c|}
\hline Item (normal range) & Day 1 & Day 2 & Day 3 & Day 4 & Day 5 & Day 6 & Day 7 & Day 8 \\
\hline Platelets (150-400x10.3/ $\mathrm{\mu L}$ ) & 415 & 226 & 99 & 32 & 19 & 17 & 48 & 106 \\
\hline INR (1-1.1) & & 1.1 & 1.2 & 1.3 & 2.9 & 3 & 2.4 & 1.7 \\
\hline D-Dimer (less than $0.46 \mathrm{mg} / \mathrm{L})$ & & & 4.48 & & 23.26 & & & 35.2 \\
\hline Fibrinogen $(1.8-3.5 \mathrm{~g} / \mathrm{L})$ & & & 2.6 & & 2.3 & & & 2.2 \\
\hline
\end{tabular}

Table 2: Coagulation profile of the patient in week 1. 


\section{References}

1. Pomero F, Di Minno MN, Fenoglio L, Gianni M, Ageno W, et al. (2015) Is diabetes a hypercoagulable state? A critical appraisal. Acta Diabetol 52: $1007-1016$

2. Lemkes BA, Hermanides J, Devries JH, Holleman F, Meijers JC, et al. (2010) Hyperglycemia: a prothrombotic factor?. J Thromb Haemost 8: 1663-1669.

3. Megarbane B, Marsanne C, Meas T, Medeau V, Guillausseau PJ, et al (2007) Acute lower limb ischemia is a frequent complication of severe diabetic hyperosmolarity. Diabetes Metab 33: 148-152.

4. Milano A, Tadevosyan A, Hart R, Luizza A, Eberhardt M (2016) An uncommon complication of hyperosmolar hyperglycemic state: bilateral above knee amputations. Am J Emerg Med 34: 341.

5. Fayfman M, Pasquel FJ, Umpierrez GE (2017 ) Management of Hyperglycemic Crises: Diabetic Ketoacidosis and Hyperglycemic Hyperosmolar State. Med Clin North Am 101: 587-606.

6. Li MF, Ren Y, Zhao CC, Zhang R, Li LX, et al. (2014) Prevalence and clinical characteristics of lower limb atherosclerotic lesions in newly diagnosed patients with ketosis-onset diabetes: a cross-sectional study. Diabetol Metab Syndr 3: 6-71
7. Shah B, Rockman CB, Guo Y, Chesner J, Schwartzbard AZ, et al. (2014) Diabetes and vascular disease in different arterial territories. Diabetes Care 37: $1636-1642$

8. Verma H, Meda N, Vora S, George RK, Tripathi RK (2014) Contemporary management of symptomatic primary aortic mural thrombus. J Vasc Surg 60: $1524-1534$

9. Caron F, Anand SS (2017) Antithrombotic therapy in aortic diseases: A narrative review. Vasc Med 22: 57-65.

10. Scott AR; Joint British Diabetes Societies (JBDS) for Inpatient Care; JBDS hyperosmolar hyperglycaemic guidelines group (2015) Management of hyperosmolar hyperglycaemic state in adults with diabetes. Diabet Med 32: 714-724.

11. Butt T, Gottsater A, Apelqvist J, Engstrom G, Acosta S (2017) Outcome of intra-arterial thrombolysis in patients with diabetes and acute lower limb ischemia: a propensity score adjusted analysis. J Thromb Thrombolysis 44: 475-480.

12. Knuger T, Liske B, Ziemer S, Lindemann S, Ziemer G (2011) Thrombolysis to treat thrombi of the aortic arch. Clin Appl Thromb Hemost 17: 340-345. 